\title{
Hemophilia A in a Senior Patient: A Case Report of Spinal Epidural Hematoma as First Presentation
}

\author{
Dong Ki Ahn, Woo Shik Jung, Jae Il Lee \\ Department Orthopedics, Seoul Sacred Heart General Hospital, Seoul, Korea
}

Hemophilia A is a hereditary coagulation disorder. Most cases are diagnosed at birth or at least during childhood. A spontaneous spinal epidural hematoma was developed in a 74-year-old male patient who hadn't had a family or past medical history of bleeding disorders. On magnetic resonance imaging, epidural hematoma at L1-2 was accompanied by spinal stenosis at L4-5 and spondylolytic spondylolisthesis at L5. Hematoma evacuation and surgery for distal lumbar lesions were performed at once. After transient improvement, complete paraplegia was developed due to redevelopment of large epidural hematomas at L1-2 and L4-S1 which blocked epidural canal completely. Emergency evacuation was performed and we got to know that he had a hemophilia A. Factor VIII was $28 \%$ of normal value. Mild type hemophilia A could have not been diagnosed until adulthood. Factor VIII should have been replaced before the surgical decompression.

Keywords: Hemophilia A; Hematoma; Epidural; Spinal; Spontaneous; Senior

\section{Introduction}

Hemophilia A is a coagulation disorder inherited as Xlinked recessive trait. The severity is decided by the level of the active clotting factor VIII. Mild cases show only a trauma or a surgery related hemorrhage. Amidst nervous system hemorrhage, a spinal epidural hemorrhage (SHE) develops far less than an intracranial hemorrhage. Furthermore, SEH as a first symptom is extremely rare. Most cases previously reported were episodes in children. We experienced a spontaneous SEH in a senior patient. After a surgical debacle, we discovered hemophilia A in our patient.

\section{Case Report}

A 74-year-old male patient suffering from severe back and both legs radiating pain was transferred to our hospital. The magnetic resonance imaging (MRI) taken at the previous hospital showed an epidural mass at L1-2. Besides, there was a spinal stenosis at L4-5 and a spondylolytic spondylolisthesis at L5 (Fig. 1). The patient had suffered from neurogenic claudication for the last 10 years and had received epidural steroid injections from time to time. Eleven days before his transfer he was troubled due to multiple tryouts of an epidural injection. Severe back pain and both legs radiating pain were developed after that night. MRI was done the next day and SEH compressing the cauda equina was found at L1-2. The conservative treatment failed to ameliorate the symptoms. Thus, he was transferred to our hospital. On neurological examination, there was a diffuse sensory decrease in the left lower extremity, the motor power was intact. On laboratory findings, platelet count, bleeding time, clot-

Received May 25, 2014; Revised Jul 6, 2014; Accepted Jul 18, 2014

Corresponding author: Dong Ki Ahn

Department of Orthopedic Surgery, Seoul Sacred Heart General Hospital, 259 Wangsan-ro, Dongdaemoon-gu, Seoul 130-867, Korea

Tel: +82-2-966-1616, Fax: +82-2-968-2394, E-mail: adkajs@hanmail.net 
ting time, and prothrombin time were within normal limits. Activated partial thromboplastin time was slightly extended with 36.4 seconds (Table 1). As the patient had neither a past history of abnormal bleeding nor any medication of anti-platelet agents and there was nothing specific in his laboratory findings, we couldn't consider any bleeding disorder. His SEH was suspected to be related to the unsuccessful epidural injections. Carelessly, we did not give attention to the fact that the location of the hematoma was different from the site of epidural injections. We performed the hematoma evacuation and the surgery for L4-5-S1 simultaneously. All surgical procedures were uneventful. The symptoms had improved after the operation. However, the pain in the right leg re-developed after 6 hours. So, the MRI was retaken. During the MRI, his blood pressure dropped to $90 / 60 \mathrm{~mm} \mathrm{Hg}$ and a complete
Table 1. Profile of coagulation tests

\begin{tabular}{lc} 
Test & Measurements (normal limits) \\
\hline Platelet count $(/ \mu \mathrm{L})$ & $217,000(130,000-400,000)$ \\
Bleeding time $(\mathrm{min})$ & $1(1-4)$ \\
\hline Clotting time (min) & $3(3-5)$ \\
Prothrombin time (sec) & $9(9.2-11.9)$ \\
Active partial thromboplastin & $36.4(24.1-32.3)$ \\
time (sec) & \\
Fibrinogen $(\mathrm{mg} / \mathrm{dL})$ & $410(219-516)$ \\
\hline
\end{tabular}

paraplegia developed. The MRI showed large hematomas at L1-2 and L4-S1 compressing the cauda equina (Fig. 2). An emergency evacuation of hematomas was done. The bleeding tendency increased compared to the previous
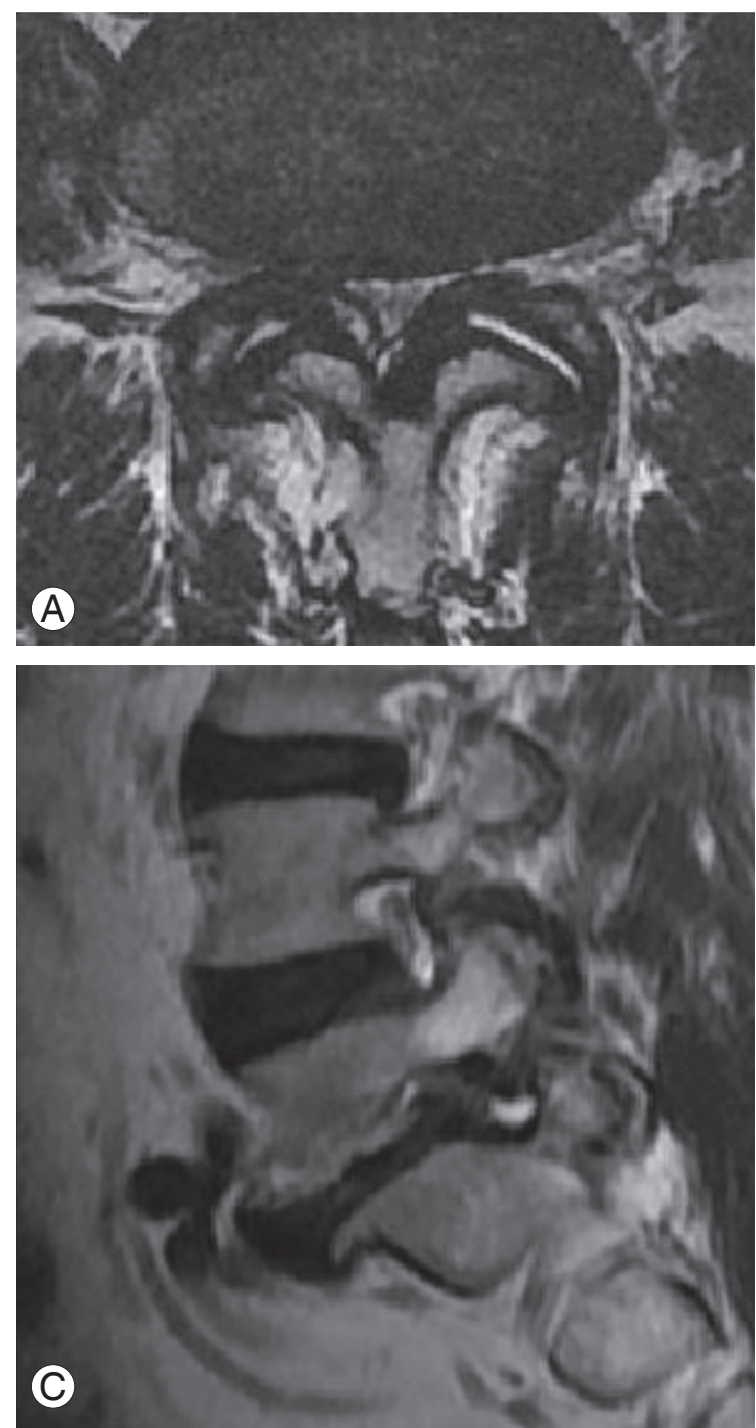

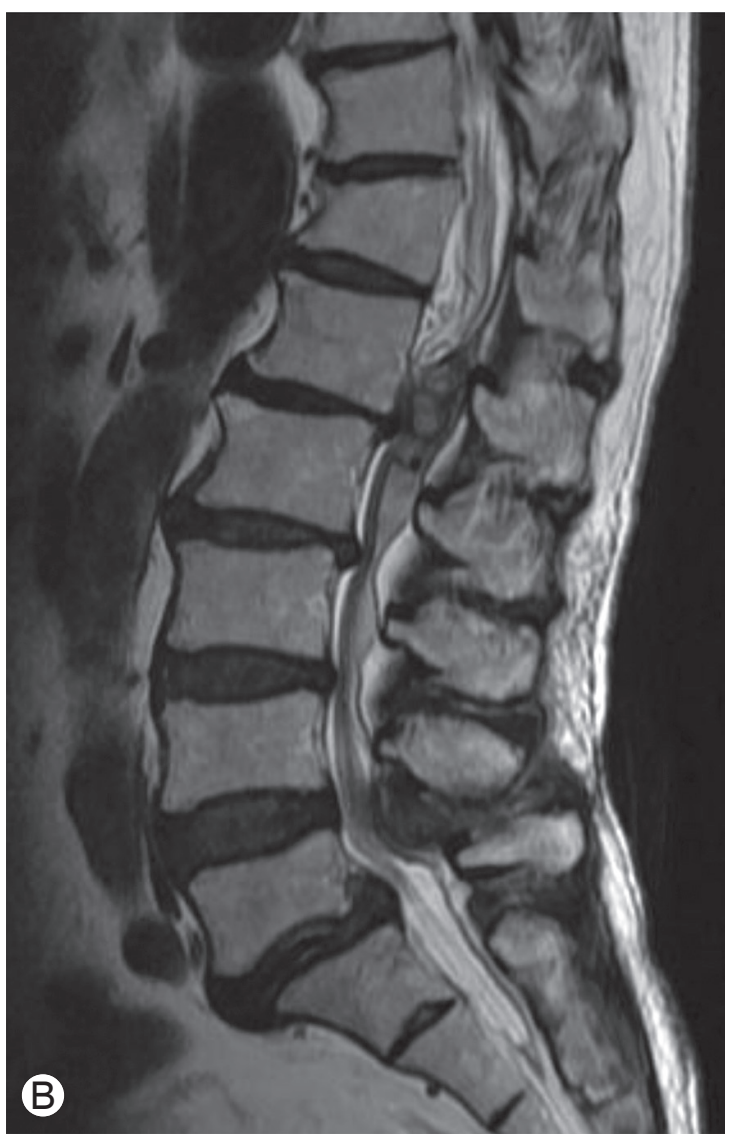

Fig. 1. (A) T2 sagittal magnetic resonance imaging which shows a heterogenous large epidural hematoma compressing the cauda equine at the L1-2 segment, $(B)$ a spinal stenosis at $\llcorner 4-5$, and (C) a spondylolytic spondylolisthesis. 
surgery. After the revision, neurological symptoms began to improve immediately. The repeated SEH raised our doubts about his bleeding tendency. Thus, we examined the clotting factors and got to know that factor VIII was $28 \%$ of normal, indicating a mild hemophilia A. The clotting factor was not replaced because there was no sign of neurological deterioration any more. At day 14 , the MRI was repeated. There were still hematomas on both sites, but there was no compression to the dura mater anymore (Fig. 3). The neurological symptoms were fully recovered at month 2 .

\section{Discussion}

Hemophilia A is inherited as X-linked recessive trait however, $30 \%$ of patients have no family history. It is considered as a new mutation of gene [1]. The degree of severity is determined by the differences in changes to the gene involved. Regarding the active clotting factor VIII, less

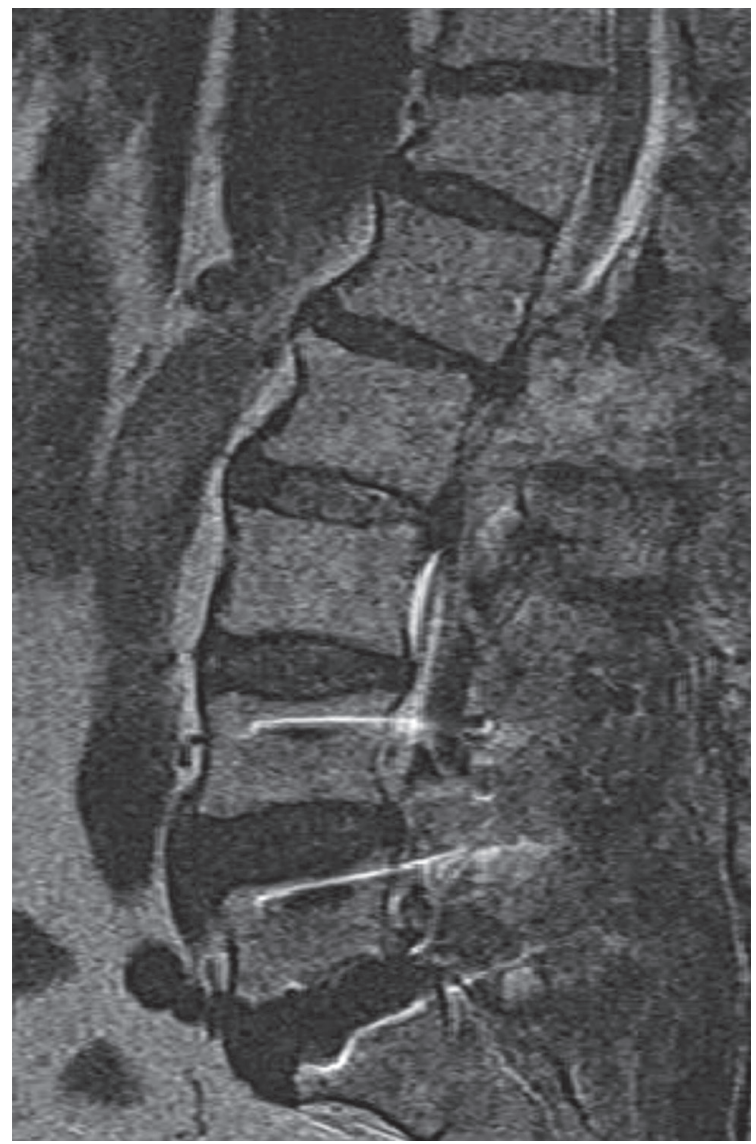

Fig. 2. T2 sagittal magnetic resonance imaging which shows large epidural hematomas at $\mathrm{L} 1-2$ and $\mathrm{L} 4-5$ segments. The dura mater was completely compressed by the epidural mass. than $1 \%$ of the normal value is classified as severe, $1 \%$ to $5 \%$ as moderate and $5 \%$ to $40 \%$ as mild. SEH is one of the complications of hemophilia [2]. The incidence of SEH is with $0.001 \%$ very rare whereas intracranial hemorrhage happens in $7.5 \%$ of hemophiliacs [3]. Most of SEHs happen among children [4]. The pathogenesis is presumed as a rupture of epidural veins. An increased abdominal or thoracic pressure can make a backflow and a rupture of veins because there is no valve system in the spinal epidural veins [5]. On scrutiny of the current case, there hasn't been any spontaneous bleeding episode. The patient's age, the absence of any family history or previous episode let us not consider a hereditary bleeding disorder. The patient was supposed to experience a surge of abdominal pressure due to the failed tryouts of an epidural injection. Given that the location of epidural hematoma was not concordant with the injection site, the cause of bleeding

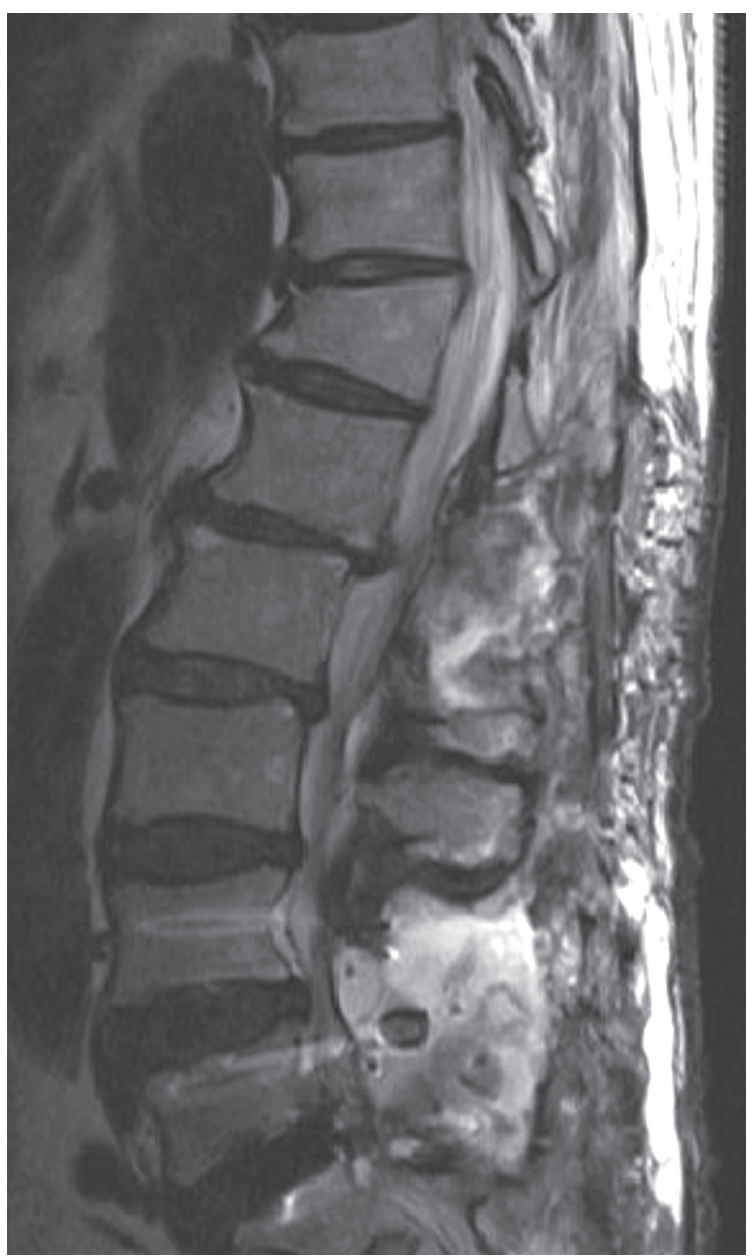

Fig. 3. T2 sagittal magnetic resonance imaging which shows the remaining hematomas at $\mathrm{L} 1-2$ and $\mathrm{L} 4-5$ segments. However, the dura mater was no more compressed. 
was supposed to be an epidural venous rupture due to a sudden rise of abdominal pressure rather than a vascular injury by a needle.

In case of an iatrogenic SEH, the early surgical decompression is a principle. However, the clotting factor should be replaced as soon as possible in hemophiliacs. Initially, it should be increased to $80 \%$ to $100 \%$ of the normal value and maintained upwards of $50 \%$ for 2 weeks $[5,6]$. There have been many reports on the successful conservative treatment of cases by the replacement of the clotting factor [7-10]. However, there have also been many reports on permanent neurological sequel $[11,12]$. Besides, only $50 \%$ of spontaneous SEH cases have been fully recovered and most significant prognostic factors were the degree of neurological defect and the time interval before a surgical decompression [13]. Therefore, the surgical decompression has to be considered according to the situation even in hemophiliacs.

The presented case has its precious lessons. We present an undiagnosed senior hemophiliac. Therefore, the careful evaluation of such conditions is necessary when a spontaneous hemorrhage is developed. Patients with spontaneous SEH may have a bleeding tendency of various reasons. For this, simultaneous surgeries should be avoided while performing decompression for hematoma. The replacement of clotting factor should be enforced before any surgery if a patient with SEH is discovered as having hemophilia.

\section{Conflict of Interest}

No potential conflict of interest relevant to this article was reported.

\section{References}

1. Bowen DJ. Haemophilia A and haemophilia B: molecular insights. Mol Pathol 2002;55:1-18.

2. Noth I, Hutter JJ, Meltzer PS, Damiano ML, Carter LP. Spinal epidural hematoma in a hemophilic infant.
Am J Pediatr Hematol Oncol 1993;15:131-4.

3. de Tezanos Pinto M, Fernandez J, Perez Bianco PR. Update of 156 episodes of central nervous system bleeding in hemophiliacs. Haemostasis 1992;22:25967.

4. Schmitz A, Wallny T, Sommer T, et al. Spinal epidural haematoma in haemophilia A. Haemophilia 1998;4:51-5.

5. Sheikh AA, Abildgaard CF. Medical management of extensive spinal epidural hematoma in a child with factor IX deficiency. Pediatr Emerg Care 1994;10:269.

6. Hamre MR, Haller JS. Intraspinal hematomas in hemophilia. Am J Pediatr Hematol Oncol 1992;14:1669.

7. Harvie A, Lowe GD, Forbes CD, Prentice CR, Turner J. Intraspinal bleeding in haemophilia: successful treatment with factor VIII concentrate. J Neurol Neurosurg Psychiatry 1977;40:1220-3.

8. Jost W, Graf N, Pindur G, Sitzmann FC. Intraspinal, extradural hemorrhage in a 7-year-old boy with hemophilia B. Monatsschr Kinderheilkd 1990;138:36-7.

9. Kiehna EN, Waldron PE, Jane JA. Conservative management of an acute spontaneous holocord epidural hemorrhage in a hemophiliac infant. J Neurosurg Pediatr 2010;6:43-8.

10. Morsing IE, Brons P, Th Draaisma JM, van Lindert EJ, Erasmus CE. Hemophilia a and spinal epidural hematoma in children. Neuropediatrics 2009;40:2458.

11. Heer JS, Enriquez EG, Carter AJ. Spinal epidural hematoma as first presentation of hemophilia A. J Emerg Med 2008;34:159-62.

12. Morichika S, Shima M, Imanaka Y, Nakajima M, Iwasaki S, Yoshioka A. Spinal canal bleeding in hemophilia A. Rinsho Ketsueki 1995;36:687-93.

13. Pecha MD, Able AC, Barber DB, Willingham AC. Outcome after spontaneous spinal epidural hematoma in children: case report and review of the literature. Arch Phys Med Rehabil 1998;79:460-3. 